\title{
KEPATUHAN BEROBAT PENDERITA TB PARU DI PUSKESMAS NGUNTORONADI I KABUPATEN WONOGIRI
}

\author{
Lissa Inggar Dewanty ${ }^{1}$, Titik Haryanti ${ }^{2}$, Tri Puji Kurniawan ${ }^{3}$
}

Fakultas Kesehatan Masyarakat, Universitas Veteran Bangun Nusantara Sukoharjo

Email : inggar.anggara17@gmail.com¹, haryanti.titik@gmail.com², tripujisiip@gmail.com ${ }^{3}$

\begin{abstract}
Abstrak. Tuberkulosis paru merupakan penyakit penyebab kematian terbesar setelah kardiovaskuler dan ISPA. Kabupaten Wonogiri menempati peringkat 2 se-Eks Karesidenan Surakarta dengan target CDR belum terpenuhi dari 2011-2014. Puskesmas Nguntoronadi I termasuk 10 besar dalam hal jumlah kasus dan angka CDR menempati peringkat 4 yaitu 35,11\%. Angka ketidakpatuhan penderita TB berobat $>50 \%$. Penelitian ini bertujuan untuk mengetahui hubungan antara karakteristik penderita TB (umur dan jenis kelamin) dan peran PMO dengan kepatuhan berobat di Kecamatan Nguntoronadi Kabupaten Wonogiri. Jenis penelitian survey analitik dengan pendekatan cross sectional study. Populasi adalah semua pasien di Puskesmas Nguntoronadi I dari tahun 2014 sampai bulan Februari 2015 berjumlah 8159 orang, dengan sampel 11 orang diambil dengan teknik purposive sampling. Variabel bebas adalah umur, jenis kelamin dan peran PMO. Variabel terikat adalah kepatuhan berobat. Analisis statistik menggunakan uji chi square dengan tingkat kepercayaan $95 \%$ atau $\alpha=0,05$. Hasil analisis univariat anakanak $(9,09 \%)$, remaja dan dewasa dewasa $(27,27 \%)$, orang tua $(63,63 \%)$, lakilaki $(63,64 \%)$, perempuan $(36,37 \%)$, PMO baik $(27,27 \%)$, buruk $(72,73 \%)$, patuh $(36,36 \%)$ dan tidak patuh $(3,64 \%)$. Tidak ada hubungan antara umur $(\mathrm{p}=0,378>0,05)$ dan jenis kelamin $(\mathrm{p}=1,000>0,05)$ dengan kepatuhan berobat penderita TB. Ada hubungan yang kuat antara peran PMO dengan kepatuhan berobat penderita TB Paru $(\mathrm{p}=0,024<0,05$ dan $\mathrm{C}=0,629)$.
\end{abstract}

Kata kunci: karakteristik penderita, $\mathrm{PMO}$, kepatuhan berobat

\begin{abstract}
Pulmonary tuberculosis is one of the leading diseases which cause death, after cardiovascular and Upper Respiratory Infection. Wonogiri district was ranked number 2 in karisidenan Surakarta and has not been met the CDR targets from 2011 to 2014. Public Health Centers of Nguntoronadi $I$ was one of the 10 health centers in terms of the number of cases and ranked 4 in number CDR with 35,11\%. Patient who had not complianced to $T B$ treatment $>50 \%$. This research aimed to determine the relationship between the characteristics of pulmonary TB patients (age and sex) and the role of the supervisor of medicine consumption (Pengawas Minum Obat$P M O)$ with treatment compliance in the Public Health Center Nguntoronadi I Wonogiri. This study was a survey research with cross-sectional approach. The population was all the patients in Public Health Centers of Nguntoronadi I from 2014 until the month of February 2015 amounted to 8150 people, with number of sampel was 11 people, who were taken by purposive sampling technique. Independent variables were age, gender, and the role of the PMO. The dependent variable was the treatment compliance. The statistical analysis used chi square tests with a confidence level of $95 \%$ or $\alpha=0,05$. The results
\end{abstract}


from the univariate analysis showed that the subject were children $(9,09 \%)$, adults and adolescent (27,27\%), and elderly (63,63\%); man (63,64\%), women (36,37\%); PMO moderate $(27,27 \%)$, low $(72,73 \%)$, obedient $(36,36 \%)$ and not obey $(3,64 \%)$. There were no relationships between age $(p=0,378>0,05)$ and gender $(p=1,000>0,05)$ with treatment compliance. There was strong relationship between the role of the PMO and treatment compliance $(p=0,007<0,05) C=0,629$.

Keywords: patient characteristic, PMO, treatment compliance

\section{PENDAHULUAN}

TB paru merupakan penyakit menular yang mengancam kesehatan masyarakat di seluruh dunia, terutama di negaranegara yang sedang berkembang. Penyebab kematian nomor tiga terbesar setelah penyakit kardiovaskuler dan penyakit infeksi saluran pernafasan atas (ISPA) pada semua golongan umur adalah TB paru. ${ }^{1}$ Indonesia menempati peringkat ketiga jumlah penderita $\mathrm{TBC}$ di dunia setelah India (1.762.000) dan China $(1.459 .000)^{2}$

Angka penemuan kasus atau CDR (Case Detection Rate) di Jawa Tengah tahun 2010 sebesar 55,38\%, 2011 sebesar 59,52\%, 2012 sebesar 58,45\% dan untuk tahun 2013 sampai dengan Tri Wulan 3 sebesar 18,93\% dengan Karisidenan Surakarta menempati peringkat 2 terbesar setelah Pekalongan. Kabupaten Wonogiri menempati peringkat dua dengan angka CDR 23,95\% tertinggi setelah Kota Surakarta 66,27\%, sedangkan kabupaten lain yang masuk dalam wilayah Karisidenan Surakarta hanya mencapai angka CDR masing-masing untuk Kabupaten Boyolali 0\%, Kabupaten Sukoharjo 12,25\%, Kabupaten Karanganyar 1,15\%, Kabupaten Sragen 14,62\% dan Kabupaten Klaten 9,43\%. ${ }^{3}$

Prosentase target dan capaian CDR (Case Detection Rate) TB Paru di Kabupaten Wonogiri dari tahun 2011 sampai tahun 2015 belum memenuhi target $(<90 \%)$. Puskesmas Nguntoronadi I termasuk dalam 10 besar Puskesmas se-Kabupaten Wonogiri dengan kasus terbanyak 50\% dibawah Puskesmas Purwantoro, Kismantoro, Giriwoyo 2,
Ngadirojo, Girimarto, Baturetno 1 dan Wonogiri 2.

Hasil survei pada tanggal 28 Februari 2015 di Puskesmas Nguntoronadi I, dengan hasil angka kematian akibat TB Paru sebesar $8,3 \%$ dan angka ketidakpatuhan $>50 \%$. Pada masa anak-anak mereka akan sulit minum obat karena pada masa intensif minum obat dilakukan setiap hari, remaja maupun dewasa juga sulit dalam mengikuti program pengobatan karena memiliki mobilitas yangn tinggi, sedangkan untuk orang tua cenderung malas dalam menjalani pengobatan yang lama (minimal 6 bulan). Faktor-faktor yang mempengaruhi kepatuhan terdiri dari ekstrinsik (lama pengobatan, jarak tempat tinggal, efek samping obat dan peran PMO) dan instrinsik (umur, jenis kelamin, tingkat pendidikan, tingkat pengetahuan dan jenis pekerjaan).

Bertitik tolak dari masalah di atas peneliti merasa tertarik untuk meneliti tentang hubungan karakteristk penderita TB Paru dengan kepatuhan berobat di Wilayah Kerja Puskesmas Nguntoronadi I Kabupaten Wonogiri.

\section{METODE PENELITIAN}

Jenis penelitian ini adalah survei analitik dengan rancangan penelitian cross sectional. Subyek penelitian ini adalah 11 penderita TB Paru pada tahun 2014 sampai bulan Februari 2015 dan teknik yang digunakan adalah purposive sampling. Variabel dalam penelitian ini adalah umur, jenis kelamin, peran PMO dan kepatuhan berobat. Teknik pengumpulan data 
dalam penelitian ini primer yang dilakukan oleh peneliti sendiri menggunakan kuesioner yang diwawancarakan kepada responden dan data sekunder diperoleh dari kartu berobat
TB Paru, hasil evaluasi kegiatan program TB Paru dan profil kesehatan. Analisa data menggunakan Uji Chi squaredan koefisien kontingensi.

\section{HASIL DAN PEMBAHASAN}

\section{Hubungan Umur dengan Kepatuhan Berobat Penderita TB Paru.}

Tabel 1 Hubungan Umur dengan Kepatuhan Berobat

\begin{tabular}{|c|c|c|c|c|c|c|c|}
\hline \multirow{2}{*}{ Umur } & \multicolumn{2}{|c|}{$\begin{array}{l}\text { Tidak } \\
\text { Patuh }\end{array}$} & \multicolumn{2}{|c|}{ Patuh } & \multirow[t]{2}{*}{ Total } & \multirow[t]{2}{*}{ Persentase } & \multirow{2}{*}{$\begin{array}{r}\text { P Value } \\
\alpha=0,05\end{array}$} \\
\hline & $\bar{n}$ & $\%$ & $\mathbf{n}$ & $\%$ & & & \\
\hline 0-14 (anak-anak) & 0 & - & 1 & 9,09 & 1 & 9.09 & \\
\hline 25-49 (remaja dan dewasa) & 2 & 18,18 & 1 & 9.09 & 3 & 27,27 & 0,378 \\
\hline$>49$ (orang tua) & 5 & 45,46 & 2 & 18,18 & 7 & 63,64 & \\
\hline Jumlah & 7 & 63,64 & 4 & 36,36 & 11 & 100 & \\
\hline
\end{tabular}

Dari hasil analisis diperoleh nilai $p$ value $0,378>0,05$ maka disimpulkan tidak ada hubungan yang signifikan antara umur dengan kepatuhan berobat penderita TB Paru di Wilayah Kerja Puskesmas Nguntoronadi I Kabupaten Wonogiri. Hasil penelitian bahwa responden didominasi oleh umur tua $(>49$ tahun), hal tersebut karena di usia tua sistem imunologis seseorang akan menurun sehingga rentan terhadap penyakit. Pada usia tua juga lebih tidak teratur menjalankan pengobatan karena kurangnya motivasi yang kuat untuk sehat dan memperhatikan kesehatannya, menjadi lebih terisolasi serta terdapat penurunan fungsi sosial seperti intelektual, memori dan kemampuan memecahkan masalah. ${ }^{4}$ Pada usia remaja dan dewasa tubuh mereka masih cenderung produktif sehingga mempunyai motivasi yang tinggi dalam mengikuti pengobatan, begitu juga dengan anak-anak yang mempunyai pengawasan dari orang tua untuk lebih patuh dalam berobat.

Kenyataan lain di lapangan responden berpendidikan rendah hanya mencapai SMP saja yang dapat mempengaruhi motivasi mereka dalam menjalani pengobatan, selain itu di usia tua mereka terserang penyakit lain seperti diabetes atau gula.

Penelitian ini sesuai dengan penelitian Erawatyningsih, dkk (2009) yang menyatakan tidak ada hubungan antara umur dengan kepatuhan berobat ${ }^{5}$ tetapi penelitian ini sesuai dengan penelitian Budiman, dkk (2010) yang menyatakan ada hubungan antara umur dengan kepatuhan berobat ${ }^{6}$. Beberapa teori mengungkapkan bahwa umur tidak mempengaruhi kepatuhan berobat tetapi lebih kepada resiko menderita TB Paru.

\section{Hubungan Jenis Kelamin dengan Kepatuhan Berobat Penderita TB Paru.}

Tabel 2 Hubungan Jenis Kelamin dengan Kepatuhan Berobat

\begin{tabular}{|c|c|c|c|c|c|c|c|}
\hline \multirow{2}{*}{ Jenis Kelamin } & \multicolumn{2}{|c|}{ Tidak Patuh } & \multicolumn{2}{|c|}{ Patuh } & \multirow{2}{*}{ Total } & \multirow{2}{*}{ Persentase } & \multirow{2}{*}{$\begin{array}{l}p \text { value } \\
\alpha=0,05\end{array}$} \\
\hline & $\mathrm{N}$ & $\%$ & $\mathrm{n}$ & $\%$ & & & \\
\hline Laki-laki & 4 & 36,36 & 3 & 27,27 & 7 & 63,63 & \\
\hline Perempuan & 3 & 27,27 & 1 & 9.09 & 4 & 36,37 & 1,000 \\
\hline Jumlah & 7 & 63,63 & 4 & 36,36 & 11 & 100 & \\
\hline
\end{tabular}

Hasil analisis diperoleh nilai $p$ kepatuhan berobat penderita TB Paru di value $=1,000>0,05$ yang artinya tidak ada Wilayah Kerja Puskesmas Nguntoronadi hubungan antara jenis kelamin dengan I Kabupaten Wonogiri. Menurut Nurvita 
(2013), penyakit Tuberkulosis Paru cenderung lebih tinggi pada laki-laki dibandingkan perempuan ${ }^{7}$. Pada jenis kelamin laki-laki penyakit ini lebih tinggi karena merokok dan minum alkohol sehingga dapat menurunkan sistem pertahanan tubuh dan mudah terpapar dengan agen penyebab penyakit TB Paru.

Laki-laki mempunyai beban kerja yang berat serta gaya hidup yang tidak sehat seperti merokok dan alkohol. Menurut Notoatmojo dalam Nurnisa (2012), menyebutkan bahwa perempuan lebih memperhatikan kesehatannya dibanding laki-laki, oleh karena itu perempuan lebih jarang terserang penyakit TB Paru. ${ }^{4}$ Erni Erawatyningsih, dkk (2009) mengemukakan bahwa perempuan lebih banyak melaporkan gejala penyakitnya dan berkonsultasi dengan dokter karena perempuan cenderung memiliki perilaku yang lebih tekun daripada lakilaki. ${ }^{5}$ Hasil penelitian bahwa jumlah laki-laki dan perempuan yang tidak patuh tidak ada perbedaan yang signifikan, karena baik lakilaki maupun perempuan mempunyai beban kerja yang sama.

Penelitian ini sesuai dengan penelitian Erawatyningsih, dkk (2009) yang menyatakan tidak ada hubungan antara jenis kelamin dengan kepatuhan berobat ${ }^{5}$ tetapi penelitian ini sesuai dengan penelitian Nurnisa (2012) yang menyatakan ada hubungan antara jenis kelamin dengan kepatuhan berobat. ${ }^{4}$

\section{Hubungan Peran PMO dengan Kepatuhan Berobat Penderita TB Paru}

Tabel 3 Hubungan Peran PMO dengan Kepatuhan Berobat

\begin{tabular}{|c|c|c|c|c|c|c|c|c|}
\hline \multirow{2}{*}{ Peran PMO } & \multicolumn{2}{|c|}{ Tidak Patuh } & \multicolumn{2}{|c|}{ Patuh } & \multirow{2}{*}{ Total } & \multirow{2}{*}{ Persentase } & \multirow{2}{*}{$\begin{array}{l}\text { P Value } \\
\alpha=0,05\end{array}$} & \multirow{2}{*}{$\mathrm{C}$} \\
\hline & n & $\%$ & $\mathbf{n}$ & $\%$ & & & & \\
\hline Buruk & 7 & 63,63 & 1 & 9,09 & 8 & 72,72 & & \\
\hline Baik & 0 & - & 3 & 27,28 & 3 & 27,28 & 0,024 & 0,629 \\
\hline Jumlah & 7 & 63,63 & 4 & 36,37 & 11 & 100 & & \\
\hline
\end{tabular}

Tabel 3 di atas dihasilkan yang paling banyak PMO buruk responden tidak patuh sebanyak 7 orang $(63,63 \%)$. Terlihat bahwa responden dengan PMO baik semuanya patuh yaitu sebanyak 3 orang (27,28\%). Anggota keluarga seharusnya lebih efektif dalam menjalankan tugas sebagai PMO seperti memberi motivasi, memberikan penyuluhan kepada anggota keluarga, mengingatkan jadwal berobat (periksa dahak dan mengambil obat) serta mengawasi penderita dalam menelan obat.

Pada jawaban kuesioner hampir semua PMO tidak pernah memberi penyuluhan kepada penderita yang mempunyai gejalagejala tersangka TB untuk memeriksakan diri ke petugas kesehatan, hal ini karena PMO tidak pernah mendapatkan penyuluhan dari petugas kesehatan berkaitan dengan penyakit responden dan tidak pernah diberi tahu tugas-tugas respoden sebagai PMO, terbukti bahwa sebagian besar responden datang ke Puskesmas hanya sendiri tidak didampingi oleh PMOnya. Biasanya petugas kesehatan akan menanyakan kepada penderita nama salah satu anggota keluarga atau orang terdekat yang dapat ditunjuk sebagai PMO namun dengan tugas hanya mengambilkan obat jika penderita berhalangan hadir.

Hasil analisis diperoleh nilai $p$ value $=$ 0,024 yang artinya ada hubungan antara peran PMO dengan kepatuhan berobat, juga nilai koefisien kontingensi sebesar 0,629 yaitu kekuatan hubungannya kuat, artinya semakin baik peran PMO maka akan semakin tinggi kepatuhan penderita dalam berobat. Hasil penelitian Erawatyningsih et al (2009), menyatakan tidak ada hubungan antara peran PMO dengan kepatuhan berobat ${ }^{5}$ tetapi sama halnya dengan penelitian Imelda (2009), yang menyatakan ada hubungan antara peran PMO dengan kepatuhan berobat tetapi hubungannya rendah. $^{8}$ 


\section{KESIMPULAN DAN SARAN}

Umurdanjeniskelamin tidakberhubungan dengan kepatuhan berobat penderita TB Paru di Wilayah Kerja Puskesmas Nguntoronadi I Kabupaten Wonogiri. Ada hubungan yang kuat antara peran PMO dengan kepatuhan berobat penderita TB Paru di Wilayah Kerja Puskesmas Nguntoronadi I Kabupaten Wonogiri.

Peran PMO sangatlah penting dalam mendukung kepatuhan penderita TB Paru dalam menjalani pengobatan yang tergolong tidak singkat (minimal 6 bulan), sehingga sebaiknya benar-benar anggota keluarga yang dpercaya dapat melakukan tugasnya dengan baik agar kepatuhan penderita TB Paru tinggi yang akan berpengaruh terhadap kesembuhan mereka. Instansi kesehatan khususnya Puskesmas Nguntoronadi I lebih menggiatkan sosialisasi dan penyuluhan kepada anggota keluarga yang ditunjuk sebagai PMO tentangtentang tugas-tugas seorang $\mathrm{PMO}$, sehingga tugas PMO dapat terlaksana dengan baik dan optimal.

Penderita TB Paru agar dapat menggali lebih banyak informasi tentang penyakitnya agar meningkatkan motivasi dalam berobat. Masyarakat juga perlu meningkatkan derajat kesehatan masing-masing dengan pola hidup bersih dan sehat agar terhindar dari penyakit seperti TB Paru. Peneliti lain perlu sampel yang lebih besar dan wilayah yang lebih luas untuk mengembangkan penelitian berikutnya.

\section{DAFTAR PUSTAKA}

Budiman, N.E., Mauliku, D.A., 2010. Analisis Faktor Yang Berhubungan Dengan Kepatuhan Minum Obat Pasien TB Paru Pada Fase Intensif Di Rumah Sakit Umum Cibabat Cimahi. Skripsi. Cimahi: Sekolah Tinggi Ilmu Kesehatan A. Yani Cimahi

Dinas Kesehatan Provinsi Jawa Tengah. 2013. Buku Saku Kesehatan. Semarang: Dinas Kesehatan Provinsi Jawa Tengah

Erni, E., Purwanta, Heru, S. 2009. Faktor-Faktor Yang Mempengaruhi Ketidakpatuhan Berobat Pada PenderitaTuberkulosis Paru. Berita Kedokteran Masyarakat. Volume 25. No. 3, September 2009, hlm 117-124

Imelda, Z. 2009. Pengaruh Karakteristik Individu, Faktor Pelayanan Kesehatan dan Faktor Peran Pengawas Menelan Obat Terhadap Tingkat Kepatuhan Penderita TB Paru Dalam Pengobatan di Puskesmas Pekan Labuhan Kota Medan. Skripsi. Medan: Fakultas Kesehatan Masyarakat Universitas Sumatera Utara

Nurnisaa, P. 2012. Hubungan Karakteristik Demografi Dengan Kepatuhan Berobat Pasien TB Paru di RS Paru Jember. Skripsi. Jember : Fakultas Kedokteran Universitas Jember.

Nurvita, P.P. 2013. Hubungan Dukungan Pengawas Minum Obat (PMO) dengan Kepatuhan Berobat Pasien Tuberkulosis Paru di Puskesmas Limboto Kabupaten Gorontalo tahun 2013. Skripsi. Gorontalo : Program Studi Ilmu Keperawatan

Rikha, N.P,M., Ari, W., Dwi, S. 2012. Hubungan Antara Karakteristik Individu, Praktik Hygiene dan Sanitasi Lingkungan dengan Kejadian Tuberkulosis di Kecamatan Semarang Utara Tahun 2011. (Online). Volume 1, Nomor. 2, (http://ejournals1.undip.ac.id/index.php/jkm diakses 24 Mei 2014)

Risa, N., Widyasari, M., Ari, W., Henry, S. 2012. Hubungan Antara Jenis Kepribadian, Riwayat Diabetes Mellitus dan Riwayat Paparan Merokok dengan Kejadian TB Paru Dewasa di Wilayah Kecamatan Semarang Utara. (Online). Volume 1, Nomor. 2, (http://ejournals1. undip.ac.id/index.php/jkm diakses 24 Mei 2014) 